\title{
Da periferia ao centro, cá e lá: seguindo trajetos, construindo circuitos
}

From the periphery to the center, here and there: following paths, building circuits

\section{José Guilherme Cantor Magnani}

\section{(2) OpenEdition}

Edição electrónica

URL: http://journals.openedition.org/aa/526

DOI: 10.4000/aa.526

ISSN: 2357-738X

\section{Editora}

Programa de Pós-Graduação em Antropologia Social (UnB)

Edição impressa

Data de publição: 31 dezembro 2013

Paginação: 53-72

ISSN: 0102-4302

\section{Refêrencia eletrónica}

José Guilherme Cantor Magnani, «Da periferia ao centro, cá e lá: seguindo trajetos, construindo circuitos», Anuário Antropológico [Online], v.38 n.2 | 2013, posto online no dia 01 fevereiro 2014, consultado o 28 abril 2021. URL: http://journals.openedition.org/aa/526 ; DOI: https://doi.org/ $10.4000 /$ aa. 526

Este documento foi criado de forma automática no dia 28 abril 2021.

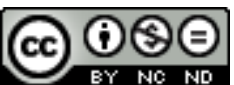

Anuário Antropológico is licensed under a Creative Commons Atribuição-Uso Não-Comercial-Proibição de realização de Obras Derivadas 4.0 International. 


\section{Da periferia ao centro, cá e lá: seguindo trajetos, construindo circuitos}

From the periphery to the center, here and there: following paths, building circuits

José Guilherme Cantor Magnani

\section{NOTA DO EDITOR}

Recebido em 22/07/2013

Aceito em 30/07/2013

1 Um dos desafios da Antropologia Urbana é construir suas unidades de análise. Diferentemente de outros campos de nossa disciplina, como é o caso dos estudos de etnologia indígena que contam com uma espécie de protocolo para a pesquisa parentesco, organização social e chefia, cosmologia, xamanismo, mitologia - os antropólogos às voltas com questões urbanas, a cada pesquisa, têm de inventar e justificar seus recortes na multifacetada paisagem das cidades contemporâneas.

2 Existe até uma expressão comumente utilizada para ajudar na escolha desta ou daquela direção: antropologia da cidade ou na cidade. Esta oposição tem origem, como se sabe, em uma das observações de Clifford Geertz sobre os alcances da descrição etnográfica. Em determinada passagem de A interpretação das culturas (1978), em que critica a tentativa de tomar pequenas aldeias e cidades "típicas" como depositárias da "essência" de civilizações, religiões, aparece a afirmação: "O lócus do estudo não é o objeto do estudo. Os antropólogos não estudam as aldeias (tribos, cidades, vizinhanças...), eles estudam nas aldeias" (:32).

3 Assim, de toda a sua discussão, que envolve os conhecidos conceitos e aforismos como "descrição densa", "os pequenos voos de raciocínio", “a análise cultural é 
intrinsecamente incompleta" etc., foi retida a oposição na versus da e estendida às pesquisas sobre questões urbanas. Nessa apropriação, o primeiro polo compreenderia aqueles estudos em que a cidade é o contexto no qual são recortados os mais variados objetos de estudo, enquanto o segundo apontaria em outra direção: a própria cidade como objeto das indagações.

4 Antes de avaliar a pertinência de uma ou outra para as pesquisas contemporâneas, porém, convém situar o próprio desenvolvimento da Antropologia Urbana no Brasil que, em seus começos, teve como principal referência a tradição de pesquisa desenvolvida pela Escola Sociológica de Chicago.

\section{Antropologia Urbana em São Paulo: ELSP e USP}

Mais especificamente na cidade de São Paulo, essa influência fez-se sentir desde a década de 1930 por intermédio da "Escola Livre de Sociologia e Política" (ELSP). Esta instituição não apenas teve como horizonte a orientação inovadora dos "etnógrafos de Chicago", conforme acertadamente os caracterizou Ulf Hannerz (1986), como ademais trouxe de lá, e de outras instituições acadêmicas norte-americanas, pesquisadores como Donald Pierson, Samuel Lowrie, Horace Davis, além de - para citar outras linhagens e procedências - Emilio Willems, Herbert Baldus e até E.B. Radcliffe-Brown.

6 Cientistas sociais de renome na cena intelectual brasileira, como Florestan Fernandes, Sérgio Buarque de Holanda, Darcy Ribeiro, Juarez Brandão Lopez, Gioconda Mussolini, Oracy Nogueira e até do exterior, como David Maybury-Lewis (posteriormente professor e investigador na Universidade de Harvard), entre outros, iniciaram seus cursos de pós-graduação na ELSP.

7 É digno de nota que a primeira investigação sobre padrão de vida e nível de consumo de trabalhadores urbanos no Brasil tenha sido coordenada, entre os anos 1934 e 1937, nessa escola, por dois pesquisadores norte-americanos, Samuel Lowrie e Horace Davis, acima citados, tendo resultado no livro As condições de vida dos funcionários da limpeza pública de São Paulo. Uma importante consequência desse estudo foi a adoção de uma metodologia que serviu de base para o estabelecimento do "salário mínimo", conhecido patamar de remuneração da classe trabalhadora (Kantor, I, Mariel, D. \& Simões, J., 2001:15).

8 Mas a orientação que terminou mesmo caracterizando sua produção foi a dos "estudos de comunidade, de que são exemplos Os Parceiros do Rio Bonito, de Antonio Candido; Uma comunidade Amazônica, de Charles Wagley; Cunha: Tradição e Transição em uma cultura rural do Brasil, de Emilio Willelms; Cruz das Almas: uma vila brasileira, de Donald Pierson, entre outros. Desta forma, diferentemente das principais produções da Escola de Chicago, no Brasil foram vilas e pequenas cidades interioranas que constituíram os objetos das pesquisas: pode-se dizer que foi Robert Redfield, e não Louis Wirth, quem deixou sua marca, ao menos no início das pesquisas da ELSP, instituição que de forma institucional e sistemática foi a responsável pela formação dos primeiros cientistas sociais brasileiros.

O outro centro universitário de projeção nesse campo, a então Faculdade de Filosofia Ciências e Letras da USP, fundada em 1934 e que veio a assumir lugar de relevo no campo das Ciências Sociais a partir dos anos 1950, também contou em seu princípio com a colaboração de professores estrangeiros, desta feita principalmente da França. Os 
nomes mais conhecidos foram Fernand Braudel, Pierre Monbeig, Roger Bastide e Claude Lévi-Strauss. Tristes Trópicos, por exemplo, tem passagens sobre a cidade de São Paulo e seus arredores - a "etnografia dos domingos", na expressão do próprio Lévi-Strauss enquanto o pioneiro estudo de Roger Bastide, Macumba Paulista, trata de uma religião considerada tipicamente brasileira e urbana.

Na USP, porém, as Ciências Sociais tomaram outra direção. Sob a liderança intelectual de Florestan Fernandes, as principais referências teóricas foram de autores como K. Mannhein, G. Simmel, M. Weber, o que terminou produzindo uma polarização entre antropologia e sociologia - aquela, vista como restrita ao trabalho de campo nos moldes dos estudos de comunidade, e esta mais voltada para métodos quantitativos e quadros conceituais universalistas.

11 A polêmica rendeu e foi só na década de 1970 que a antropologia voltou a adquirir maior espaço e visibilidade, não mais com pesquisas em pequenas vilas interioranas, mas em grandes centros urbanos. Foi a época dos chamados "movimentos sociais urbanos" quando, em razão do golpe militar de 1964, o foco da atuação política (e, em consequência, do interesse acadêmico) passou do militante ao morador, e dos partidos e sindicatos operários para associações de bairro situados na periferia, a porção mais desassistida das cidades, em comparação com as áreas centrais. ${ }^{1}$

Merece destaque o papel das mulheres nesse processo, de início ofuscado pelas lutas que ocorriam tendo como cenário principalmente o pátio e os portões da fábrica; seu espaço era o cotidiano do bairro, onde começaram a liderar movimentos como abaixoassinados por melhorias e equipamentos urbanos, tais como creches, iluminação pública, transporte coletivo etc. Em suma, o que reivindicavam era o "direito à cidade", para usar a conhecida expressão de Henri Lefebvre (1969).

13 Nessa época, as antropólogas Ruth Cardoso e Eunice Durham começaram, de forma pioneira, a discutir com seus orientandos na Faculdade de Filosofia, Letras e Ciências Humanas da USP quadros de referência teórica mais ampliados, com base em textos de Richard Hoggart, do Centro Contemporâneo de Estudos Culturais da Universidade de Birminghan, além de Antonio Gramsci, Michel Foucault, Manuel Castells, Jean Lojikine, entre outros. Foi neste contexto sensível a novos temas - a ascensão das chamadas minorias e dos movimentos sociais urbanos - e aberto a experimentos etnográficos que surge a primeira categoria que norteou minhas pesquisas sobre práticas de sociabilidade: o pedaço, desenvolvido no decorrer de uma pesquisa sobre lazer e tempo livre da classe trabalhadora em São Paulo (Magnani, 1984).

\section{As unidades de análise}

14 Não cabe aqui, contudo, voltar a esta e às demais categorias posteriormente utilizadas em pesquisas do Núcleo de Antropologia Urbana (NAU/USP) - mancha, trajeto, pórtico, circuito - já apresentadas em outros trabalhos, em especial no mais recente, Da periferia ao centro: trajetórias de pesquisa em Antropologia Urbana (Magnani, 2012). Basta uma menção ao seu percurso: como o título deste livro indica, a partir de uma incursão pioneira na periferia de São Paulo, foi possível (e necessário) ampliar o leque das categorias para dar conta da complexidade da dinâmica urbana, para além de formas de sociabilidade situadas no contexto da vizinhança, no bairro. 
15 Na verdade, tratava-se de uma necessidade ao mesmo tempo conceitual e metodológica diante de uma literatura, até mesmo nas Ciências Sociais, que enfatizava os aspectos desagregadores do processo de urbanização, principalmente no caso das grandes cidades dos países emergentes, segundo o eufemístico jargão. Muitos desses enfoques buscavam entender a dinâmica urbana a partir de variáveis econômicas, demográficas, político-institucionais - enfoques que denominei, em outro texto, como um olhar "de fora e de longe", pois encaravam a cidade mais como resultado de interesses e decisões no plano macro do que da ação dos atores sociais concretos.

16 Em contraposição a este olhar, propus o da etnografia, "de perto e de dentro", com ênfase justamente nesses atores sociais e no exercício de suas atividades cotidianas na trama da cidade - trabalho, lazer, religiosidade, participação politica e associativa etc. No entanto, havia aí um perigo, que denominei de "a tentação da aldeia": tentar reproduzir, na paisagem marcadamente heterogênea das cidades contemporâneas, aquela situação de pesquisa tradicionalmente associada ao método etnográfico - o pequeno grupo, os contatos face a face no interior de um bairro, de uma festa, de uma associação - deixando de lado o contexto mais amplo no qual essas relações se desenrolam.

17 O desafio que se colocava era o de articular duas dimensões aparentemente antagônicas: não se deixar perder no nível das particularidades nem, ao contrário, imaginar que se poderia fazer a etnografia de uma cidade inteira, de 11 milhões de habitantes, como São Paulo. Para tanto, fazia-se necessário discutir as unidades de análise.

18 As categorias acima referidas - pedaço, mancha, trajeto, pórtico, circuito - apontavam justamente nesta direção: escapar do plano de uma totalidade inabarcável, mas sem cair numa fragmentação sem fim. Pois, se não há uma única ordem que possa ser aplicada a cidades com tais escala e dimensões, não quer dizer que não haja nenhuma: a questão é estabelecer recortes em que seja possível, com os instrumentos adequados, identificar e descrever regularidades nas diferentes esferas da vida dos atores sociais que constroem a trama na qual se sustenta a dinâmica urbana.

19 São seus múltiplos e criativos arranjos coletivos, por meio dos quais transitam pela cidade, usufruem seus serviços, utilizam seus equipamentos, estabelecem encontros e trocas nas mais diferentes esferas, que constituem o ponto de partida para a análise. $O$ conhecimento que daí resulta, a partir do método etnográfico, baseia-se no pressuposto de que esse recorte tem duas faces: uma, relacionada com o agente, é a que faz sentido imediato para ele, pois é sua prática; a outra é voltada para o pesquisador, que reconhece esse sentido e o descreve, nos termos de seu quadro conceitual.

Trata-se, para usar a formulação de Marc Augé quando fala do "lugar antropológico", de uma unidade que é "simultaneamente princípio de sentido para aqueles que o habitam e princípio de inteligibilidade para quem o observa" (1994:51). Do ponto de vista do agente, é um "arranjo", resultado de escolhas em face de um repertório de alternativas; já o observador o reconhece, o segue e, no processo de investigação, o refere a outros recortes, quando então constitui uma "unidade de análise" em outro nível.

21 Quem já estudou terreiros de candomblé, galeras de jovens, escolas de samba, torcidas organizadas de futebol, o circuito gay, manchas de lazer etc. sabe que estes e outros casos análogos apresentam fronteiras e graus de pertencimento vivamente experimentados 
pelos integrantes do grupo. Tomando como exemplo a categoria de pedaço, é evidente, por parte de seus integrantes, uma percepção imediata, sem nuanças ou ambiguidades, a respeito de quem pertence ou não a ele: trata-se de uma experiência concreta e compartilhada. 0 pesquisador, por sua vez, percebe tal experiência e a descreve: essa modalidade particular de encontro, troca e sociabilidade supõe a presença de elementos mínimos estruturantes que a tornam reconhecível em outros contextos.

Assim, uma unidade consistente em termos da etnografia é aquela que, experimentada e reconhecida pelos atores sociais, é identificada pelo investigador, podendo ser descrita em seus aspectos mais gerais, constitutivos. Para os primeiros, é o contexto da experiência e, para o segundo, a chave de inteligibilidade e o princípio explicativo. Uma vez que não se pode contar com unidades dadas a priori, postula-se uma a ser construída a partir da experiência dos atores e com a ajuda de hipóteses de trabalho e escolhas teóricas, como condição para que se possa dizer algo mais que generalidades a respeito do objeto de estudo.

Desta forma, aqueles dois planos a que se fez alusão mais acima, o da cidade em seu conjunto e o de cada prática cultural associada a este ou àquele grupo de atores em particular - ou, nos termos inicialmente apresentados, antropologia da ou na cidade devem ser considerados como polos de uma relação que circunscrevem, determinam e possibilitam a dinâmica do objeto que se estuda.

Para captar os vários planos dessa dinâmica, por conseguinte, é preciso

situar o foco nem tão de perto que se confunda com a perspectiva particularista de cada usuário, e nem tão de longe a ponto de distinguir um recorte abrangente mas genérico e sem rendimento explicativo. Em outros termos, nem no nível puramente macro, nem no das escolhas individuais: há planos intermediários nos quais se pode distinguir a presença de padrões, de regularidades e, para captá-los, é preciso modular o olhar. Entre o "de fora e de longe" e o "de perto e de dentro" certamente há nuanças e gradações que permitem variar ângulos e escalas da observação.

\section{Dois casos}

A apresentação, a seguir, de dois relatos poderá complementar o argumento acima desenvolvido. O primeiro deles, "O mundo dos surdos", é um bom exemplo de como um objeto de pesquisa é construído: antes da aplicação das categorias, identificando aí as unidades de análise, sequer existia. Relegados aos consultórios de otorrinos e fonoaudiólogos e, quando muito, citados em algum artigo da literatura médica, os surdos eram praticamente invisíveis na paisagem urbana. A etnografia mostrou os lugares que frequentam, os trajetos que fazem, os circuitos que articulam seus pontos de encontro na cidade. No outro exemplo sai-se de São Paulo em direção à Amazônia e, neste caso, o desafio era aplicar aquelas categorias, forjadas no contexto de uma grande metrópole, à outra paisagem e a outros personagens: os índios urbanos. ${ }^{2}$

\section{0 mundo dos surdos}

26 A descoberta dos surdos deu-se a partir de um convite feito ao NAU para integrar um grupo de pesquisa formado por linguistas e historiadores da USP. O pedido era para contribuir com o enfoque antropológico - e em especial com o da Antropologia Urbana 
- para uma pesquisa já em andamento, que incluía descrição da língua de sinais brasileira (Libras) por parte dos linguistas e registro de histórias de vida, por parte dos historiadores.

Mais concretamente, o que se pretendia era poder identificar a rede de encontros e sociabilidade dos surdos na cidade a partir das categorias utilizadas em pesquisas do Núcleo de Antropologia Urbana. O mês em que ocorreu o convite também teve seu papel nos rumos que essa participação seguiu. Era época das festas juninas que tomam conta de escolas, instituições, associações de bairros, igrejas, clubes em todo o Brasil, e a pergunta que se colocava era: as escolas e as associações de surdos também promovem essas comemorações? Outra indagação, inevitável, logo veio à tona: festa junina de surdo tem música? ${ }^{3}$

28 Para quem havia estudado diferentes formas de lazer na cidade,${ }^{4} \mathrm{o}$ estudo das festas não apenas é um recorte obrigatório como ademais constitui sempre uma via de acesso privilegiada para o entendimento das regras que estão na base de redes de sociabilidade. Desta forma, com o auxílio dessas categorias, foi possível descrever o cenário das festividades: inicialmente, a noção de pedaço permitiu entender a dinâmica de duas delas, uma realizada pela ADEFAV (Associação para Deficientes da AudioVisão) na rua em frente a seu endereço, no bairro do Cambuci, e a da Associação dos Surdos de São Paulo, Vila Clementino.

29 Mas havia diferenças. No primeiro caso, o espaço da festa era uma extensão das dependências da associação, que servia de retaguarda (banheiro, cozinha) e oferecia a infraestrutura básica: barraquinhas, mesas, cadeiras e o pequeno palco. Como a ADEFAV atende, além de surdo-cegos, crianças multideficientes, essa proximidade garantia o fornecimento de cuidados extras para seu público específico. Mas por ser realizada na rua, teve caráter mais aberto, permitindo maior interação entre os participantes - pais, amigos, convidados - enquanto na segunda, a Associação dos Surdos, quem não era mesmo do pedaço não se sentia à vontade; os sinais de reconhecimento eram mais estritos.

E foi o que me aconteceu. Tendo chegado cedo, para não perder nenhum detalhe da "Festa do Cowboy", procurei um bom lugar de observação no interior do pequeno sobrado onde fica a sede dessa associação. Contudo, sem o devido conhecimento da língua de sinais, passei ali mais de duas horas solenemente ignorado pelos surdos que chegavam e logo se enturmavam - afinal, era o seu pedaço - enquanto para mim, bem, restou o consolo (sempre se aproveita algo) de reconhecer ter sido vivamente afetado (à la Faivre-Saada, 1990) pela mesma experiência que eles têm quando em ambientes frequentados por ouvintes, o que, aliás, é a regra em seu cotidiano na cidade.

31 Já o Instituto Santa Teresinha, escola especial para surdos de orientação católica no bairro da Saúde, constitui o epicentro de uma mancha que inclui quadra poliesportiva, bares nas ruas adjacentes e em suas esquinas, pontos de ônibus, todos tomados por surdos tanto nas festas - quando sua presença é massiva - quanto no dia a dia. A experiência ali foi de outra ordem: a dinâmica da mancha, diferentemente do pedaço, permite mais contato entre os frequentadores, que são variados - no caso dessa festa, eram os surdos com seus parentes, amigos, professores, além de intérpretes, pesquisadores, religiosos: as possibilidades de entrosamento e trocas são maiores, mesmo sem o domínio de Libras. E para o pesquisador, representou uma imersão, como o trecho do caderno de campo ilustra: 
Como um estrangeiro, caminhava no meio deles apreciando as rodinhas dos grupos de amigos, os casais, as conversas, a forma como estavam vestidos; pelo fato de não dominar a língua de sinais, não me prendi a nenhum grupo, nem procurei decifrar o que diziam; interessava-me, nesse momento, fazer uma imersão nesse ambiente novo, cujo código básico de comunicação me era estranho. Como eram as regras de etiqueta? Pode-se passar no meio de uma roda de conversa? Como pedir desculpas por um esbarrão?

[...] restavam-me outros códigos e outros planos de observação, sendo obrigado a apurar o olhar, já que os significados não podiam vir por intermédio do som. São raros esses momentos na experiência etnográfica: a prática mostra que aos poucos se vai adentrando no universo do outro, que acaba perdendo essa capacidade de maravilhar e torna-se familiar ao observador.

Num determinado momento, subi os degraus da arquibancada que fica diante da quadra onde rolava a festa e, lá de cima, tive acesso a um espetáculo realmente inusitado: a disparidade entre a multidão e o barulho que deveria estar fazendo, se fosse uma festa de ouvintes; em contraste, havia um fervilhar de mãos numa espécie de frenética pantomima, ao menos aos olhos de um leigo. Em termos plásticos e coreográficos, o espetáculo era realmente impressionante e me perguntei se o efeito do barulho, da algaravia, da música no último volume sobre um ouvinte seria da mesma ordem, em termos até de uma experiência extática, ao efeito produzido pelo "mar de mãos" sobre uma pessoa surda (Magnani, 2012:26-227).

mancha, com maior variedade de personagens, as inter-relações mudam e as estratégias de comunicação são outras. Com os trajetos, escolhem seus pontos de encontro, enfrentam seus conflitos ou os produzem. No circuito, amplia-se mais o círculo de possibilidades, permitindo que o "mundo dos surdos" ${ }^{5}$ seja visto em suas múltiplas 
articulações com os espaços, as instituições e os equipamentos urbanos - e não de forma indiferenciada, homogênea.

Assim, foi possível dar contornos a um universo constituído por uma série diversificada de atores sociais, práticas, regulamentos, associações, equipamentos e agências, ao menos no horizonte e no estado atual da pesquisa sobre esse tema em São Paulo. Estava-se, agora, diante de unidades de sentido consistentes, capazes de abrigar matizes, comportamentos e presença na paisagem urbana: o circuito dos equipamentos em que se realizam as festas juninas, num calendário amplamente conhecido no mundo surdo, como se viu, é exemplo, em outra escala, de uma dessas unidades de sentido, assim como o das instituições religiosas, com suas diferenças nas formas de evangelização (o ministério dos surdos das Igrejas Batistas, o das Testemunhas de Jeová e a pastoral dos surdos da Igreja Católica), cada qual com implicações para a rede de sociabilidade dos surdos. ${ }^{6}$

\section{Os circuitos dos Sateré-Mawé}

Um novo desafio foi a utilização de algumas dessas categorias para analisar uma questão - a presença de índios em contextos urbanos - ausente ou um tanto residual nos estudos correntes de etnologia indígena. Para situar a dimensão do problema, cabe ressaltar, inicialmente, que de acordo com dados do censo de 2010 sobre a população indígena no Brasil divulgado pelo Instituto Brasileiro de Geografia e Estatística (IBGE), de um total de 896.900 pessoas, 315.180 , ou seja, $36,2 \%$, vivem em cidades. Em Manaus, capital do estado com maior número de indígenas em termos absolutos (183.514), essa população, segundo diversas estimativas, varia entre 6.000 mil a 20.000 pessoas provindas de diferentes regiões do Estado, destacando-se, entre os grupos mais numerosos, os Ticuna e Cokama, do Alto Solimões, os Tucano, Baré, Dessana e Tariano, do Alto Rio Negro, e os Sateré-Mawé, do Médio Amazonas (Teixeira, Pery et alii, 2009:540).

Os Sateré-Mawé habitam tradicionalmente uma região situada na área de cinco municípios, entre os estados do Amazonas e Pará: Barreirinha, Parintins, Maués, Itaituba e Aveiro, e que foi homologada como terra indígena em 1986. Sua língua integra o tronco linguístico Tupi e o contato remonta ao século XVII, mas é a partir da década de 1970 que sua presença se faz notar nas cidades da região e na capital do estado do Amazonas. A geração mais nova participa da vida urbana, fala português, frequenta escolas públicas; no entanto, os Sateré, em suas comunidades urbanas, mantêm as tradições e os vínculos com as aldeias nas T.I.

39 As abordagens mais convencionais sobre a situação dos índios que vivem em áreas urbanas detêm-se, preferencialmente, sobre as precárias condições de vida, trabalho e sobrevivência, comuns a quaisquer outros moradores de baixa renda que vivem na periferia dos centros urbanos: é possível, entretanto, encarar esse fenômeno sob outro prisma: tal foi o propósito das pesquisas que o GEU - Grupo de Etnologia Urbana do NAU, vem desenvolvendo desde 2009, inicialmente em Manaus e arredores. ${ }^{7}$

Assim, em vez de circunscrever a presença indígena no contexto habitual do processo de periferização urbana, com instável inserção no mercado de trabalho, confinamento em regiões de risco e carente de serviços e equipamentos básicos, o que se propunha era repensar a cidade a partir das estratégias e das soluções encontradas pelas diferentes etnias que nela habitam. Mais concretamente, pretendia-se indagar que 
transformações sua presença acarretaria na própria dinâmica da cidade e como nela estabelecem suas redes de sociabilidade e inscrevem seus trajetos em busca de instituições, alianças e estratégias para manutenção de um modo de vida diferenciado.

41 Nas primeiras idas a campo em Manaus, contudo, foram os eixos do lazer e tempo livre - seguindo uma tradição nos estudos do NAU - que orientaram o olhar e as escolhas e, de pronto, três práticas e espaços de encontro e sociabilidade chamaram a atenção: o futebol, uma festa/ritual de iniciação e as feiras de artesanato. ${ }^{8}$ Contudo, logo após um tempo de observação e convivência, foi ficando evidente que aspectos inicialmente óbvios - entretenimento, num caso, e venda de produtos como fonte de recursos, no outro - não esgotavam a questão.

o futebol, que a literatura mostra ser uma atividade muito disseminada nas populações indígenas, mesmo nas áreas tradicionais demarcadas, em Manaus aparecia também num quadro institucional mais amplo, o "Peladão", famoso torneio de futebol amador que mobiliza a cidade toda, inclusive os índios. 0 mesmo aconteceu com o artesanato: passar dos pontos de venda para o processo de produção e para as redes de distribuição abriu um campo insuspeitado, revelando redes de troca, coleta e aquisição de sementes, entre outros aspectos.

Aquela modalidade esportiva, sem dúvida, pode ser enquadrada na categoria de lazer, pois é praticada regularmente com igual entusiasmo por indígenas das mais variadas etnias, homens e mulheres, com seus vizinhos não índios nos campos de terra perto de suas moradias - seus pedaços - ou naqueles situados em quadras poliesportivas. Contudo, a participação oficial de uma chave indígena, desde 2005, no Peladão introduziu novas conotações, mostrando um importante espaço de disputas, afirmação e encontro: a formação dos times, a definição de quem é ou não é índio, a que etnia pertence, as acusações mútuas denunciando a presença de "brancos" no time do adversário, as representações sobre o estilo de jogar dos índios por oposição ao dos não índios etc.

Todo ano esse campo de disputa se renova e a presença indígena na cidade ganha importante visibilidade, podendo-se concluir que, neste caso, o futebol, mais que uma forma de entretenimento, é um dispositivo que produz significados, estabelece distinções, gera categorias de acusação e de pertencimento.

Em relação ao artesanato, trata-se de uma atividade realizada principalmente por mulheres no ambiente doméstico, nas brechas dos afazeres de casa ou em grupo, na sede de alguma associação, com filhos pequenos em volta, em clima de conversa e descontração. Sem dúvida é um trabalho, fonte de renda para o orçamento familiar, mas o quadro em que se insere é muito mais amplo que seu aspecto econômico: a coleta da matéria-prima faz-se ao longo de trajetos em busca principalmente de sementes na vegetação de parques, praças, terrenos baldios, devidamente mapeados na paisagem da cidade, além das que se obtêm por intermédio de parentes residentes em aldeias das terras indígenas e de membros de outras etnias. E assim se instaura um novo e extenso circuito.

$\mathrm{E}$, finalmente, o ritual da Tucandeira, ritual de passagem masculino em que meninos e jovens, em meio a danças e cânticos, devem enfiar as mãos em duas luvas de palha trançada repletas de formigas, após o que são considerados "verdadeiros guerreiros". É um ritual complexo e trabalhoso, que aciona também um amplo circuito, pois é preciso convidar os candidatos dispostos a colocarem as mãos na luva; contatar um bom mestre de cerimônia, geralmente da terra indígena, para conduzir os cantos e as danças; 
buscar, retirar e tratar as formigas a serem inseridas nas luvas que, depois de tecidas, devem ser adornadas com penas de gavião real e arara vermelha, materiais de difícil obtenção.

É preciso ainda obter as polpas de jenipapo necessárias no preparo da tintura para os grafismos corporais, organizar o espaço na comunidade para a realização do ritual e receber visitantes (parentes, vizinhos, pesquisadores, imprensa) - o que inclui levantar barracas para venda de artesanato, comidas e bebidas típicas, montar o palco para apresentações musicais e até os alvos para disputas de arco e flecha, bem ao gosto de turistas... Enfim, trata-se de uma série de atividades que demandam tempo, dinheiro, uma rede de relações e conhecimentos específicos.

Só estes três aspectos da presença dos Sateré-Mawé em Manaus - futebol, artesanato e Tucandeira - configuram complexos circuitos por onde transitam humanos e não humanos, parentes da cidade e das terras indígenas, lideranças e políticos, estudantes e professores, visitantes e vizinhos. Está muito distante da visão de pobres índios confinados na periferia: eles têm agência, deixam suas marcas, transitam por extensas redes de sociabilidade que vão além do perímetro urbano convencional.

Desta forma, seguindo esses diferentes trajetos dos Sateré-Mawé, foi possível estabelecer um circuito mais geral e mais estável que articula suas unidades residenciais, inicialmente em Manaus e arredores - Y'apyrehy e Waikiru, mais a sede da AMISM (Associação das Mulheres Indígenas Sateré-Mawé) - depois as mais afastadas, já em área de floresta - I'nhaã-bé, Hywy, no Tarumã-Açu, braço do igarapé do Tiú; Waranã, no município de Manaquiri e Sahu-Apé, em Iranduba. Mais tarde, na medida em que o contato se ampliava, foram agregadas as Casas de Trânsito de Parintins e de Barreirinha e, na continuação, algumas aldeias da T.I. em Ponta Alegre.

Assim, a experiência urbana dos Sateré-Mawé, em vez de confinada a determinados espaços numa cidade pronta (e hostil) e plotada em alguma representação cartográfica fixa, tem seus contornos próprios e dialoga com as dos Tukano, dos Tikuna, dos Kambeba, dos Mura - isso para pensar numa Manaus indígena - e também com a cidade dos demais moradores, não índios, que também têm seus próprios trajetos nos diferentes circuitos formados pelo universo do trabalho, pelas agências de saúde, pelas instituições de ensino, cultura, lazer etc.

51 Vistas separadamente, ou numa visão macro da cidade - "de fora e de longe" - essas formas de inserção podem parecer irrelevantes mas, quando articuladas, constituem "unidades de sentido" e "princípios de inteligibilidade" que esclarecem sobre os modos de ser sateré: abrem pistas sobre as marcas que eles deixam numa paisagem mais ampla que inclui cidade, floresta, rios e flexibilizam suas fronteiras. Como se pode comprovar, nada a ver com aquela visão que os confina em bairros de periferia, carentes.

Mas podem dizer também algo, por contraste e comparação, sobre São Paulo, de cuja análise emergiram tais categorias, e esta é uma das possibilidades que um estudo deste tipo oferece: poder colocar e testar o rendimento, em diferentes contextos, de categorias que permitam superar a oposição antropologia da cidade versus $n a$ cidade $\mathrm{e}$ avançar no entendimento do que caracteriza, hoje, diferentes formas e modos urbanos de se viver. 


\section{Conclusão}

53 Ao longo dos dois casos sucintamente apresentados, as categorias pedaço, trajeto, mancha e circuito foram testadas em cada nova situação. Na verdade, a primeira tentativa já tinha sido a transposição, da periferia em direção ao centro, da categoria pedaço, que lá permitira descrever uma forma de sociabilidade com base numa particular relação entre o espaço e os atores sociais envolvidos. No entanto, percebeu-se que, diferentemente do contexto do bairro, onde o importante era ser conhecido por meio de laços de vizinhança, parentesco e coleguismo, pertencer a um pedaço no centro significava ser reconhecido através da exibição de símbolos cuidadosamente compartilhados.

54 O mesmo sucedeu com as demais categorias que, ao desvelarem novas formas de sociabilidade e uso do espaço nas pesquisas que se seguiram sobre outros temas, como religiosidade, culturas juvenis, estudos da comunidade surda, índios urbanos, foram também objeto de reflexão e ajustes. Articuladas entre si, são justamente as ligações e as passagens entre seus domínios que permitem levar em conta, no recorte da pesquisa, as escalas das cidades, os diferentes planos da análise e as interconexões das redes de sociabilidades. Constituem, em suma, uma gramática que permite classificar e descrever a multiplicidade das escolhas e os ritmos da dinâmica urbana não centrados nas escolhas de indivíduos, mas em arranjos mais formais em cujo interior se dão essas escolhas.

Foram descritas algumas situações encontradas no trabalho de campo que forneceram outra perspectiva para o entendimento da dinâmica urbana, em contraposição a certa visão que enfatiza o caos urbano, bastante corrente na mídia, ou à imagem dos muros e enclaves fortificados. Em vez da anomia, do isolamento ou da fragmentação, o que se vê são regularidades, arranjos coletivos, oportunidades e espaços de trocas e encontros. Esse plano da dinâmica urbana, contudo, só se manifesta a um olhar que se posiciona "de perto e de dentro", expressão com a qual denominei a postura etnográfica em uma das etapas da pesquisa, buscando identificar unidades de análise consistentes na multifacetada paisagem e heterogênea paisagem urbana.

56 E, para finalizar, cabe uma retomada da questão referida logo no começo deste artigo antropologia na ou da cidade? No primeiro caso, seria a diversidade das práticas proporcionadas pelos fatores escala e heterogeneidade que faz da cidade um campo fértil para o recorte de temas de pesquisa tão variados como gênero, relações raciais, geracionais, religiosidade, rituais da política, modalidades de lazer e sociabilidade etc. No segundo, a partícula "da" pode incluir tanto as abordagens que tomam a cidade como uma forma específica de assentamento (distinta, por exemplo, da aldeia) quanto estudos de suas partes constitutivas, como o sistema viário, a distribuição da população e dos equipamentos urbanos no território, a formação de periferias, o fenômeno da conurbação e a dinâmica dos bairros e das regiões centrais.

Os dois casos aqui descritos, surdos e índios urbanos, certamente se encaixam melhor na primeira alternativa: foram suas estratégias de uso, inserção e ocupação do espaço urbano que constituíram o foco da análise. Como, aliás, acontece com a maior parte dos estudos e das pesquisas amplamente classificadas como Antropologia Urbana. Nas palavras de Eunice Durham (2004):

Esse tipo de investigação [com populações urbanas] tem uma longa tradição na antropologia brasileira. E, desde o começo, trata-se menos de uma antropologia da 
cidade do que de uma antropologia na cidade. Isto é, não se desenvolveu no Brasil uma antropologia urbana propriamente dita, nos moldes em que foi iniciada pela Escola de Chicago, uma tentativa de compreender o fenômeno urbano em si mesmo. Ao contrário, trata-se de pesquisas que operam com temas, conceitos e métodos próprios da antropologia, mas voltados para o estudo de populações que vivem nas cidades. A cidade é, portanto, antes o lugar da pesquisa do que seu objeto (:361-362).

A opção pelo primeiro termo da oposição não quer dizer, contudo, que a cidade seja um mero cenário onde transcorrem as práticas sociais. Na verdade, a paisagem urbana é o resultado dessas práticas e das intervenções ou modificações impostas pelos mais diferentes atores (poder público, corporações privadas, associações, grupos de pressão, moradores, visitantes, equipamentos, rede viária, mobiliário urbano, eventos etc.) em sua complexa rede de trocas. Tal resultado, sempre em processo, constitui, por sua vez, um repertório das possibilidades que ou compõem o leque para novos arranjos ou, ao contrário, surgem como obstáculos. A ênfase em um ou outro termo da relação paisagem ou atores - caracteriza enfoques de outras disciplinas, enquanto a Antropologia Urbana trabalha com e na interseção de ambos, cabendo à etnografia captar esse duplo movimento.

Por outro lado, enfoques que levam também em conta a topologia ou os aspectos morfológicos não necessariamente ficam restritos à paisagem, como se pode ver em trabalhos sobre contraposições entre periferia (São Paulo) e morro (Rio), sociabilidade nas superquadras (Brasília), lazer em shopping-centers, condomínios fechados, espaços centrais "gentrificados" etc. - com importantes contribuições para o entendimento da dinâmica urbana.

E apesar da suposta incompatibilidade contida nessa dicotomia, não há porque exagerar a oposição: os termos podem ser complementares. Penso que uma antropologia na cidade, com sua multiplicidade de recortes empíricos, pode caminhar na direção de, ou contribuir para uma nova e instigante perspectiva da cidade. Para tanto, é preciso que se disponha a construir modelos mais gerais, buscando identificar e descrever quais elementos mínimos definem uma forma urbana, em seus aspectos mais estruturais e que a distinguem por exemplo, de outras formas canônicas de assentamento humano, de mais longa duração, como a aldeia e o acampamento.

61 Mas será que não seria também o caso de se perguntar, como fez Habermas (144:1992), se o próprio conceito de cidade já não estaria ultrapassado - principalmente se tendo em vista a escala e as dimensões das grandes metrópoles contemporâneas? Para este autor, a propósito de uma polêmica entre modernismo e pós-modernismo na arquitetura, a cidade da Alta Média, descrita por M. Weber, e a renascentista, da nobreza italiana - por sua vez reformada pelos arquitetos barrocos - sedimentaram um conceito de cidade e um determinado modo de vida a ela associado: "Enquanto um mundo abarcável, a cidade pôde ser arquitetonicamente formada e representada para os sentidos", o que quer dizer que as funções sociais da vida urbana - nos seus aspectos econômicos, políticos, culturais, de práticas religiosas, da vida cotidiana no âmbito do morar, da recreação, da festa - podiam ser vivenciadas e percebidas num marco temporal e espacial claramente configurado. Contudo, já "no século XIX ao mais tardar, a cidade torna-se ponto de interseção de relações funcionais de outra espécie". A vida urbana é cada vez mais mediada por "conexões sistêmicas não configuráveis" e "as aglomerações urbanas emanciparam-se do velho conceito de cidade ao qual, no entanto, se apega nosso coração" (:123, passim). 
sabe seguindo os Sateré-Mawé em seus trajetos por aldeias, cidades, florestas e rios, e percorrendo os circuitos que a partir daí se configuram, seja possível pensar novos conceitos, se não de cidade, em especial, ao menos do que seja habitar (dwelling), segundo o sentido que Tim Ingold $(2000 ; 2007)$ dá ao termo... ${ }^{9}$

\section{BIBLIOGRAFIA}

AUGÉ, Marc. 1994. Não lugares: introdução a uma antropologia da supermodernidade. Campinas: Papirus.

BASTIDE, Roger. 1973 [1946]. Macumba paulista. Col. Estudos Afro-Brasileiros. São Paulo: Perspectiva.

BECKER, Howard. 1982. Art Worlds. California: University of California.

CANDIDO, Antonio. 1964. Os parceiros do Rio Bonito: estudo sobre o caipira paulista e as transformações dos seus meios de vida. Rio de Janeiro: José Olympio.

DURHAM, Eunice. 2004. A dinâmica da cultura. São Paulo: Cosac Naify.

FAVRET-SAADA, Jeanne. 2005 [1990]. “Être affecté". Gradhiva, 8: 03-10.

HABERMAS, Jürgen. 1992. “Arquitetura moderna e pós-moderna”. In: Otília Arantes \& Paulo E. Arantes. Um ponto cego no projeto moderno de Jürgen Habermas. São Paulo: Brasiliense.

GEERTZ, Clifford. 1978. A interpretação das culturas. Rio de Janeiro: Zahar.

HANNERZ, Ulf. 1996. Exploración de la ciudad. México: Fondo de Cultura Económica.

INGOLD, Tim. 2000a. The Perception of the Environment. Essays on Livelihood, Dwelling and Skill.

London/ New York: Routledge.

. 2000b. Lines; a Brief History. London/ New York: Routledge.

KANTOR, Íris; MACIEL, Débora \& SIMÕES, Júlio A. (orgs.). 2001. A Escola Livre de Sociologia e Política: anos de formação, 1933-1953. São Paulo: Escuta.

LEFEBVRE, Henri. 1969. O direito à cidade. São Paulo: Documentos.

LÉVI-STRAUSS, Claude. 1981 [1955]. Tristes Trópicos. Lisboa: Edições 70 [São Paulo: Martins Fontes].

MAGNANI, José Guilherme C. 1998 [1984]. Festa no pedaço: cultura popular e lazer na cidade. São Paulo: Brasiliense [3. ed. Hucitec].

2007. "Vai ter música?: para uma antropologia das festas juninas de surdos na cidade de São Paulo”. Ponto Urbe, Revista Digital do Núcleo de Antropologia Urbana da Universidade de São Paulo, 1(1). Disponível em: <http://www.n-a-u.org/pontourbe/>.

MAGNANI, José Guilherme C.; ASSIS SILVA, César \& TEIXEIRA, Jacqueline. 2008. “As festas juninas no calendário de lazer de jovens surdos na cidade de São Paulo”. In: Célia T. Lucena \& Maria Christina de S. Campos. Questões ambientais e sociabilidades. São Paulo: Humanitas/ Fapesp. 
MAGNANI, José Guilherme C. 2012. Da periferia ao centro: trajetórias de pesquisa em Antropologia Urbana. Coleção Antropologia Hoje. São Paulo: Ed. Terceiro Nome.

“Índios em contextos urbanos: o caso de Manaus e outras cidades da Amazônia”. In: Carlos Fortuna \& Rogério Leite Proença. Diálogos Urbanos: Territorialidades, Culturas, Patrimónios. Coimbra: Ed. Almedina.

PIERSON, David. 1951. Cruz das Almas, a Brazilian Village. Washington: Smithsonian Institute.

TEIXEIRA, Pery; MAINBOURG, Evelyne \& BRASIL, Marilia. 2009. “Migração do povo indígena Sateré-Mawé em dois contextos urbanos distintos na Amazônia”. Caderno CRH, 22(57): 1-16.

WAGLEY, Charles. 1988. Uma comunidade amazônica: estudo do homem nos trópicos. Belo Horizonte: Edusp/ Ed.Itatiaia.

WILLEMS, Emilio. 1947. Cunha: tradição e transição em uma cultura rural do Brasil. São Paulo: Secretaria da Agricultura.

\section{NOTAS}

1. Não há espaço aqui para registar todo o desenvolvimento deste ramo da antropologia no Brasil, que deveria incluir, por certo, centros de pesquisa situados em Recife, Rio de Janeiro, Brasília, Porto Alegre e outros. De todo modo, não se pode deixar de mencionar a presença de Anthony e Elisabeth Leeds no Rio de Janeiro nos anos 1940 que, além de autores da Escola de Chicago, principalmente vinculados ao interacionismo simbólico, como Irving Goffman e Howard Becker, marcaram as pesquisas de Gilberto Velho e seus alunos no Museu Nacional da Universidade Federal do Rio de Janeiro.

2. Ambos os casos foram já objeto de publicações anteriores: é delas que retiro alguns dados e considerações que constam deste item: sobre os surdos, ver Magnani (2007) e sobre índios urbanos, Magnani (2013). Sobre a expressão "índios urbanos", cabe observar que não há consenso sobre a justeza de seu uso; uma alternativa, "índios na cidade", dá a impressão de uma mera passagem pela cidade, quando, no caso dos Sateré-Mawé, por exemplo, são já três gerações morando em Manaus.

3. Cf. Magnani, 2007 e Magnani, Assis Silva e Teixeira, 2008.

4. Cf. Festa no Pedaço: cultura popular e lazer na cidade (Brasiliense, 1984 [3 $3^{\mathrm{a}}$ edição, Hucitec, 1998]).

5. Expressão utilizada no sentido que lhe dá Howard Becker (1982).

6. Em relação à pergunta feita mais acima, se festa de surdo tem música, veja-se Magnani (2012:229).

7. Cabe assinalar que este trabalho foi possível a partir da participação do NAU no projeto "Paisagens ameríndias - Habilidades, mobilidade e sociabilidade nos rios e cidades da Amazônia" (PROCAD USP/UFAM). De janeiro de 2009 a outubro de 2012, a equipe do NAU realizou várias viagens e expedições a campo: oito em equipe de três até seis pesquisadores e cinco em duplas ou individuais. Começamos em Manaus, mas esperávamos, a médio prazo, incluir as cidades próximas da Terra Indígena de Andirá-Marau (Parintins, Barreirinha, Maués), no baixo Amazonas, para trabalhar com diversas escalas urbanas e, assim, avançar na elaboração de modelos mais gerais de análise dos deslocamentos e das estratégias de inserção deste e de outros coletivos indígenas no contexto da Amazônia urbana contemporânea.

8. Rodrigo Chiquetto e Ana Luísa Sertâ dedicaram-se, respectivamente, ao tema do futebol e do artesanato feminino, enquanto José Agnello de Andrade estudou o ritual da Tucandeira. A análise aqui feita tem como base informações de seus relatos de campo, que são compartilhadas por todos os membros do GEU. 
9. Este autor, retomando a discussão de De Certeau, considera que é importante não perder a dimensão de movimento das trajetórias: em sua dwelling perspective, Ingold defende uma concepção de lugar como um nó de linhas de movimento e crescimento, múltiplas e entrelaçadas, de modo que as pessoas não apenas ocupam, mas habitam os lugares nos quais vivem [dwell]. As trajetórias, por sua vez, podem ser pensadas como jornadas construídas [wayfaring] ao longo dos caminhos, nas quais há uma íntimaconexão entre percepção, locomoção e produção de sentidos (Ingold, 2007:78). Adotando a dwelling perspective de Ingold, é possível perceber os diferentes lócus por onde circulam os Saterés não como pontos pré-determinados, conectados numa rota vazia de sentido, mas articulados ao longo de um circuito em contínua e mútua produção. Isto nos permite pensar as relações entre floresta, terra indígena e cidade não em oposição, mas como malhas [meshworks] tecidas pelos trajetos de seus habitantes: (...) "the inhabited world is a reticulate meshwork of such trails, which is continually being woven as life goes on along them". (idem, ib.: 81)

\section{RESUMOS}

Tendo como pano de fundo os inícios da Antropologia Urbana no Brasil, com ênfase em duas instituições, a Escola Livre de Sociologia e Politica e o Departamento de Ciências Sociais da USP, o artigo apresenta as categorias de análise desenvolvidas pelo Núcleo de Antropologia Urbana, em sua proposta "de perto e de dentro" como estratégia para lidar com a diversidade da dinâmica urbana das grandes metrópoles sem cair na "tentação da aldeia", isto é, a multiplicação de estudos de caso. A utilização dessas categorias a dois recortes etnográficos - o "mundo" dos surdos na cidade de São Paulo e o circuito dos Sateré-Mawé, na região de Manaus e cidades do baixo Amazonas - como tentativa de testar sua aplicabilidade em novos contextos, levanta a questão da dicotomia "antropologia da ou na cidade", cuja proposta de superação é discutida no final do artigo.

Having as background the beginnings of Urban Anthropology in Brazil, with emphasis on two institutions, the Escola Livre de Sociologia e Politica and the Departamento de Ciências Sociais/ USP, the article presents the categories of analysis developed by the Nucleus of Urban Anthropology, in its proposal "from near and within" as a strategy to deal with the diversity of urban dynamics of large metropolises without falling into the "temptation of the "village", i.e. the multiplication of case studies. The use of these categories in two ethnographic situations the "world" of the deaf in the city of São Paulo and the circuit of the Sateré-Mawé in the Manaus region and cities low Amazon - as an attempt to test its applicability in new contexts, raises the question of the dichotomy "Anthropology of or in the city," whose proposal for overcoming is discussed at the end of the article.

\section{ÍNDICE}

Palavras-chave: antropologia urbana, categorias de análise - manchas, surdos, Sateré-Mawé Keywords: Urban anthropology, categories of analysis, deaf, Sateré-Mawé 


\section{AUTOR}

\section{JOSÉ GUILHERME CANTOR MAGNANI}

NAU/USP José Guilherme C. Magnani é Professor Titular de Antropologia da USP, autor de Festa no Pedaço: cultura popular e lazer na cidade; Da Periferia ao Centro: trajetórias de pesquisa em Antropologia Urbana e organizador de Na Metrópole: textos de Antropologia Urbana. É coordenador do NAU e editor da revista PONTO.URBE. Contato: jmagnani@usp.br 